\section{An Indo Mediterranean diet was more effective than a conventional prudent diet in reducing coronary artery disease risk factors and events}

Singh RB, Dubnov G, Niaz MA, et al. Effect of an Indo-Mediterranean diet on progression of coronary artery disease in high risk patients (Indo-Mediterranean Diet Heart Study): a randomised single-blind trial. Lancet 2002;360:1455-61.

QUESTION: In patients with, or at high risk of, coronary artery disease (CAD), is an Indo Mediterranean diet more effective than the conventional step 1 National Cholesterol Education Program (NCEP) prudent diet?

\section{Design}

Randomised (unclear allocation concealment), blinded \{clinicians, data collectors, and outcome assessors\},* controlled trial with 2 year follow up.

\section{Setting}

Moradabad, India.

\section{Patients}

1000 patients aged $>25$ years (mean age 49 y, 90\% men) with $\geq 1$ major risk factor for CAD (hypercholesterolaemia, hypertension, diabetes mellitus, angina pectoris, or previous myocardial infarction [MI]). Exclusion criteria included cancer, chronic diarrhoea or dysentery, blood urea concentrations $>6.6 \mathrm{mmol} / \mathrm{l}$, arthritis, dislike of the intervention diet, and refusal of laboratory testing. Follow up was $98 \%$.

\section{Intervention}

499 participants were allocated to follow an Indo Mediterranean diet of $\geq 400-500 \mathrm{~g} / \mathrm{d}$ of fruits, vegetables, and nuts; $400-500 \mathrm{~g} / \mathrm{d}$ of whole grains, legumes, rice, maize, and wheat; and 3-4 servings/d of mustard seed or soy bean oil (intervention group) plus a step 1 NCEP type prudent diet $(<30 \%$ energy from total fat, $<10 \%$ energy from saturated fat, and $<300 \mathrm{mg}$ cholesterol daily). 501 participants were allocated to the step 1 NCEP type prudent diet alone. Patients in both groups were advised to walk briskly for $\geq 3-4 \mathrm{~km} / \mathrm{d}$ or jog intermittently for $\geq 10-15$ minutes/d, to avoid alcohol and cigarettes, and to practice mental relaxation techniques.

\section{Main outcome measures}

Fatal or non-fatal MI, sudden cardiac death, and total cardiac endpoints (combined total MI and sudden cardiac death).

\section{Main results}

Analysis was by intention to treat. At 2 years, the intervention group consumed more fruits, vegetables, nuts, and legumes (mean $573 v 231 \mathrm{~g} / \mathrm{d}, \mathrm{p}<0.001$ ), consumed more n-3 fatty acids (mean $1.8 v 0.78 \mathrm{~g} / \mathrm{d}$, $\mathrm{p}<0.001$ ), and had lower serum cholesterol concentrations (mean 5.04 v $5.59 \mathrm{mmol} / \mathrm{l}, \mathrm{p}<0.001$ ) than the control group. The intervention group had lower risks of non-fatal MI, sudden cardiac death, and total cardiac endpoints than the control group; groups did not differ for fatal MI (table).

\section{Conclusion}

In patients with, or at high risk of coronary artery disease (CAD), an Indo Mediterranean diet rich in whole grains, fruits, vegetables, and nuts reduced CAD risk factors and total cardiac events more than a conventional prudent diet.

\footnotetext{
*Information provided by author.
}

Indo Mediterranean (Indo Medit) diet v control diet in patients with, or at high risk of, coronary artery diseaset

\begin{tabular}{llcll} 
Outcomes & Indo Medit & Control & $\begin{array}{l}\text { Adjusted RRR } \\
(95 \% \text { Cl) } \ddagger\end{array}$ & $\begin{array}{l}\text { Unadjusted NNT } \\
\text { (Cl) }\end{array}$ \\
Non-fatal MI & $4.2 \%$ & $8.6 \%$ & $53 \%(21$ to 72$)$ & $23(13$ to 73$)$ \\
\hline Fatal Ml & $2.4 \%$ & $3.4 \%$ & $33 \%(-42$ to 69$)$ & Not significant \\
\hline Sudden cardiac death & $1.2 \%$ & $3.2 \%$ & $67 \%(14$ to 87$)$ & $50(25$ to 533$)$ \\
\hline Total cardiac endpoints & $7.8 \%$ & $15 \%$ & $52 \%(29$ to 67$)$ & 14 (9 to 29$)$ \\
\hline
\end{tabular}

$+\mathrm{MI}=$ myocardial infarction; total cardiac endpoints = combined total of non-fatal and fatal $\mathrm{MI}$, and sudden cardiac death; other abbreviations defined in glossary. Unadjusted NNTs and Cls calculated from data in article. †RRRs adjusted for several baseline characteristics.

\section{COMMENTARY}

The protective effect of the Mediterranean diet in developed nations is becoming recognised as an important lifestyle strategy for reducing progression of CAD. ${ }^{1}$ However, risk factors for CAD are also an important cause of disease in developing nations. ${ }^{2}$ Research on lifestyle modification in these countries is limited, and the study by Singh et al provides important new information.

Firstly, although differences in culture, religion, geography, and resources influence dietary patterns, the Mediterranean diet can be adapted to local conditions. The Indo Mediterranean diet, although similar to the Mediterranean diet, is distinguished by its focus on fruits, vegetables, nuts, and whole grains. Secondly, such a diet, in addition to other lifestyle changes, can reduce morbidity and mortality from heart disease compared with a prudent diet. Although $2 / 3$ of patients in both the treatment and control groups were vegetarian at the start of the trial, the lifestyle modifications incorporating an Indo Mediterranean diet were still effective. Thirdly, the study findings reinforce recommendations in the developed world that consuming a variety of fruits, vegetables, and grain products will reduce risk factors of heart attack. ${ }^{3}$ Whether the Indo Mediterranean diet itself would be broadly acceptable in developed nations is moot, as dramatic alterations in diet would probably be required.

2 limitations need to be considered. $90 \%$ of participants were men, and therefore the effect of the Indo Mediterranean diet and other lifestyle changes on women remains uncertain. The acceptability of lifestyle modification for women in developing nations also needs to be investigated before lifestyle trials can be done. A second limitation is that participants were discouraged from smoking and alcohol use, and encouraged to exercise and use mental relaxation techniques. Although the frequency of these lifestyle changes apparently did not differ, these factors have also been found to have benefits in the prevention and progression of heart disease. The absence of an adjusted analysis means it is not possible to isolate potential interactions between these factors.

Singh et al provide compelling evidence for promoting diets that incorporate aspects of the Mediterranean with local diets for developing nations. Making minor adaptations is likely to facilitate adoption of dietary recommendations. Based on this study, nurses should promote additional whole grain consumption and expanded food choices in patient education.

Sek Ying Chair, RN, CCRN, MSN, MBA Assistant Professor, The Nethersole School of Nursing The Chinese University of Hong Kong, Hong Kong, China

1 American Heart Association. Lyon Diet Heart Study. http://www.americanheart.org/ presenter.jhtml?identifier $=4655$

World Health Organization. The World Health Report 2002. Reducing risks, promoting healthy life. Geneva: World Health Organization, 2002. http://www.who.int/whr/2002/ Overview E.pdf

3 American Heart Association. Dietary guidelines for healthy American adults. http://www.americanheart.org/presenter.jhtml?identifier=4561 